\title{
A Practice-Sponsored Web Site to Help Patients Pursue Healthy Behaviors: An ACORN Study
}

Steven $H$. Woolf, $M D, M P H^{1}$

Alex H. Krist, $M D^{2}$

Robert E. Jobnson, $\mathrm{PbD}^{3}$

Diane B. Wilson, EdD, MS, RD

Stephen F. Rothemich, MD, $M S^{2}$

Gregory J. Norman, PbD

Kelly J. Devers, $P b D^{5}$

'Departments of Family Medicine, Epidemiology, and Community Health, Virginia

Commonwealth University, Richmond, Va

${ }^{2}$ Department of Family Medicine, Virginia Commonwealth University, Richmond ${ }_{i}$ Fairfax Fmily Practice Residency, Fairfax, Va

${ }^{3}$ Departments of Biostatistics and Family Medicine, Virginia Commonwealth University, Richmond, Va

${ }^{4}$ Department of Medicine, Virginia Commonwealth University, Richmond, Va

${ }^{5}$ Department of Family and Preventive Medicine, University of California, San Diego, San Diego, Calif

${ }^{6}$ Departments of Health Administration and Family Medicine, Virginia Commonwealth University, Richmond, Va

Conflicts of interest: none reported

\section{CORRESPONDING AUTHOR}

Steven H. Woolf, MD, MPH

Department of Family Medicine

West Hospital

1200 E Broad St

PO Box 980251, MCV Station

Richmond, VA 23298-0251

swoolf@vcu.edu

\begin{abstract}
PURPOSE We tested whether patients are more likely to pursue healthy behaviors (eg, physical activity, smoking cessation) if referred to a tailored Web site that provides valuable information for behavior change.

METHODS In a 9-month pre-post comparison with nonrandomized control practices, 6 family practices ( 4 intervention, 2 control) encouraged adults with unhealthy behaviors to visit the Web site. For patients from intervention practices, the Web site offered tailored health advice, a library of national and local resources, and printouts for clinicians. For patients from control practices, the Web site offered static information pages. Patient surveys assessed stage of change and health behaviors at baseline and follow-up (at 1 and 4 months), Web site use, and satisfaction.

RESULTS During the 9 months, 932 patients (4\% of adults attending the practice) visited the Web site, and 273 completed the questionnaires. More than 50\% wanted physician assistance with health behaviors. Stage of change advanced and health behaviors improved in both intervention and control groups. Intervention patients reported greater net improvements at 1 month, although the differences approached significance only for physical activity and readiness to change dietary fat intake. Patients expressed satisfaction with the Web site but wished it provided more detailed information and greater interactivity with clinicians.
\end{abstract}

CONCLUSIONS Clinicians face growing pressure to offer patients good information on health promotion and other health care topics. Referring patients to a welldesigned Web site that offers access to the world's best information is an appealing alternative to offering handouts or impromptu advice. Interactive Web sites can facilitate behavior change and can interface with electronic health records. Determining whether referral to an informative Web site improves health outcomes is a methodological challenge, but the larger question is whether information alone is sufficient to promote behavior change. Web sites are more likely to be effective as part of a suite of tools that incorporate personal assistance.

Ann Fam Med 2006;4:148-152. DOI: 10.1370/afm.522.

\section{INTRODUCTION}

$\mathrm{F}$ our unhealthy behaviors-poor diet, physical inactivity, tobacco use, and problem drinking - constitute the leading causes of death in the United States, ${ }^{1}$ but clinicians face obstacles in helping patients to pursue behavior change. ${ }^{2}$ The barriers include too little time with patients, limited reimbursement, and uncertainties about the effectiveness of the low-intensity interventions that most practices can deliver. ${ }^{3-8}$

One challenge is connecting patients with the information resources they need to pursue healthy behaviors. Having been encouraged by clinicians to change their lifestyle, patients often seek details regarding techniques, motivational strategies, resources, and community programs, but the information that clinicians can provide in their offices is often limited, 
outdated, or commercially biased. Increasingly, consumers want information to be tailored and interactive. For their part, practices lack the time and resources to assess systematically the health behaviors of patients, their individual stages of readiness to change, or the type of assistance that patients need. ${ }^{9}$

Both inefficiency in connecting patients with individually tailored information and systematically assessing behaviors and patient expectations can benefit from Web site technology. ${ }^{10} \mathrm{~A}$ Web site for patients could host the best information available on healthy lifestyle and liberate practices from the need to keep such materials on file. The Web site would enable the practice to extend educational outreach beyond the time and place of the clinical encounter, empowering patients with convenient access to the most appropriate information as and when they need it. Interactive sites can also collect information on individuals' health behaviors and expectations. Whether a Web site performing these functions would facilitate behavior change is unclear.

We developed and tested the effectiveness of such a Web site, with support from the Robert Wood Johnson Foundation Prescription for Health program. ${ }^{11}$ The My Healthy Living (MHL) Web site (http://www.myhealthyliving.net) combined 4 features: (1) an intake assessment that collected a behavioral history and assessed stage of readiness to change ${ }_{i}(2)$ an individually tailored resource library with links to Web pages from national organizations and agencies; (3) links to local resources, including Web services offered by patients practices; and (4) tailored health advice and printouts for clinicians.

\section{METHODS}

During the course of 9 months, 6 primary care practices ( 4 intervention and 2 control) encouraged adults with unhealthy behaviors to visit the MHL Web site. Web site visitors completed a behavioral history. Intervention and control conditions were assigned nonrandomly. Patients from intervention practices were directed to Web pages with extensive health promotion resources, whereas patients from control practices were directed to static pages with limited information. In a pre-post comparison at intervention and control practices, data on health behaviors, readiness to change, and user satisfaction were obtained from e-mail questionnaires sent to patients 1 and 4 months after their first Web site visit. Participating practices were affiliated with the Virginia Ambulatory Care Outcomes Research Network (ACORN). ${ }^{12} \mathrm{We}$ detail our methods in the Supplemental Appendix,

available online-only at http://www.annfammed. org/cgi/content/full/4/2/148/DC1.

\section{RESULTS}

The Supplemental Appendix provides a full report of our study findings. In summary, 932 patients visited the MHL Web site, of whom 29\% $(n=273)$ enrolled in the study (an estimated 25,488 unique adults attended the practices during the 9 months). The small number of recruited patients compromised the statistical power of the study. Among this subgroup, substantial majorities reported physical inactivity and unhealthy diet, and most $(77 \%$ to $94 \%)$ classified themselves in preaction stages. More than one half of the patients $(55 \%$ and $53 \%$, respectively) wanted their physician's help with diet or physical inactivity.

Four months after their first Web site visit, stage of change and health behaviors had improved in patients at both the intervention and control practices. Intervention practice patients reported greater improvements at 1 month than did control practice patients, a nonsignificant trend across multiple behaviors (Figure 1). The difference at 1 month reached or approached statistical significance in relation to light to moderate physical activity (stage, $P=.02$; behavior, $P=.10$ ) and readiness to change dietary fat intake $(P=.06)$, but no significant differences persisted at 4 months. Users liked the Web site; $64 \%$ said that it was helpful, and $52 \%$ revisited 2 to 5 times. To improve the MHL Web site, users recommended more detailed information and interactivity with clinicians.

\section{DISCUSSION}

Clinicians and practices face a growing need to offer patients high-quality information on both lifestyle change and other health care topics. ${ }^{14}$ Referring patients to a well-designed Web site offers a more complete and systematic alternative to the conventional practice of offering impromptu advice during the visit or distributing the handouts that happen to be in the office. The Web site can give patients instantaneous access to the world's best information, which they can browse leisurely and at their convenience. The public has grown accustomed to using personal computers and other technology to manage personal affairs in most aspects of daily life. ${ }^{15}$ The inability to do the same in the personal management of health and health care grows increasingly problematic.

Interactive sites not only empower the consumer with greater control over knowledge but can also offer layered information that can individualize guidance, track progress, and support behavior change as needs and stages of change evolve with time. Personal health records, into which patients enter their own historical and clinical data, provide a tool for health maintenance and can interface with electronic health records and other practice information technologies. ${ }^{16}$ The secure 


\section{Figure 1. One-month behavior change among intervention and control patients.}

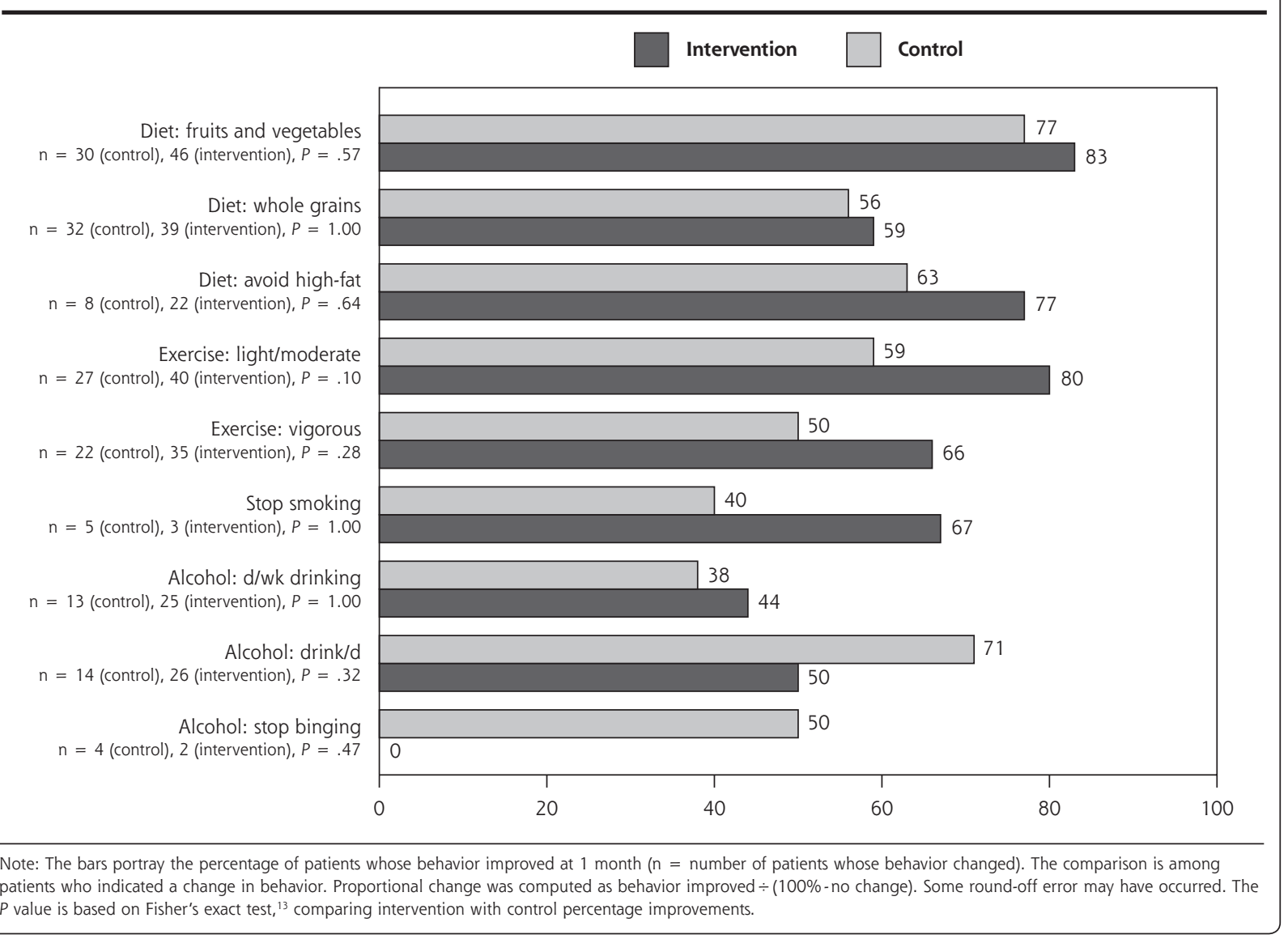

integration of practice and consumer information systems offers a modern vehicle for merging what were once separate interventions, eg, patient education, decision aids, patient reminders, and clinician prompts.

These potential benefits may account for the enduring interest in the MHL Web site beyond completion of the study. The practices that participated have since requested that the Web site remain in operation as an ongoing service to their patients. Our group, along with other practice-based research networks, is using an upgraded version of the MHL Web site in a second round of studies funded by the Robert Wood Johnson Foundation Prescription for Health program. ${ }^{17} \mathrm{Net}$ works in other states have expressed interest in providing access to the MHL Web site for their patients.

What remains unclear, however, is whether exposure to such a Web site improves health outcomes. The results of our study, detailed in the Supplemental Appendix, suggest a salutary effect on stage of change and health behaviors, but statistical power to measure a clear effect was lacking because of the relatively small number of Web site visitors. Only $4 \%$ of adult patients visited our Web site. This low visit rate was surprising in the face of high Internet use in the local popula- tion ${ }^{18}$ and apparent enthusiasm for the Web site among patients. For example, patients rapidly exhausted practices' supplies of pads with tear-off sheets listing the Web site address. Practices and clinicians vigorously encouraged patients to visit the Web site. ${ }^{19}$

In the Supplemental Appendix, we put the low Web site visit rate in context, citing, for example, the small subset of patients for whom MHL was intended. We review circumstances that may have tempered the number of Web site visitors and diluted the observed effect on stage of change and health behaviors, including possible shortcomings in practice promotion of the Web site, server failures, limited representation of young adults, the short (9-month) observation period, and contamination of the control group. The Supplemental Appendix describes other study limitations, such as its nonrandom design.

Our data therefore cannot clarify whether the low rate of visits to the MHL Web site is a generalizable indictment of patient interest in health promotion Web sites or reflects some aspect of our technique or promotional strategy. In the Supplemental Appendix we discuss strategies not used in our study that might have increased the utility and use of the Web site. Future 
studies should identify the most effective features to motivate patients to visit (and return to) Web sites for health information. Until then, our operational premise for developing the MHL Web site-if you build it, patients will come-remains an open question until a Web site with optimal features is evaluated in a study with the proper design.

The larger question, however, is whether information alone, provided by a Web site or by other media, is sufficient to help patients sustain long-term behavior change. Directing patients to a Web site with no further follow-up (eg, telephone, e-mail, office visit) may be inadequate to change lifestyle. Most MHL users classified themselves in preaction stages (for diet and physical inactivity), but $45 \%$ to $68 \%$ were in the precontemplation or contemplation stages. These patients may lack the motivation to alter their lifestyle or sustain changes based only on the information they view on a Web site and without social and environmental supports (eg, familial), personal counseling, and follow-up.

Indeed, one would not expect a single intervention to change behavior. ${ }^{20}$ Rather, electronic tools to help patients access information would presumably yield their greatest benefit as part of an integrated suite of tools that practices would offer patients, preferably in a stepwise fashion based on personal needs. ${ }^{21-23}$ The Web site might be used in isolation by patients who are self-motivated and comfortable with computers, or in combination with other options by patients who seek personal contact or more intensive assistance for motivation and support. For example, in an ongoing Prescription for Health study, we are testing such a multicomponent intervention in which the MHL Web site is among several options (telephone counseling, e-counseling, group classes) from which patients can choose to obtain more intensive assistance with behavior change.

Whether Web sites are an essential component of the suite of interventions that practices should offer patients, the need for an effective set of options is mounting. The prevalence of obesity in the United States is climbing dramatically. ${ }^{24,25}$ Primary care physicians face not only a public health imperative to address health behaviors but also consumer demand. More than $50 \%$ of our patients in this study wanted assistance with health behaviors, primarily physical activity and diet. Responding to this need with a menu of helpful options appears crucial to accommodate variability in patients' needs. The capability of Web sites to assemble and individualize high-quality resources makes these sites important to consider in the ensemble of options.

The unintended consequences of the MHL model deserve attention along with its potential benefits. For example, clinicians who refer patients to a Web site for health promotion might grow inattentive to lifestyle issues and make unfounded assumptions that patients are receiving the counseling and support that they need. If technologies such as MHL take lifestyle issues off the agenda of the patient-clinician encounter, clinicians may become less attuned to behavioral risk factors that are pertinent to illness care. Finally, the costs to practices of establishing Web sites are substantial; much of the $\$ 125,000$ grant that supported this study was devoted to creating the Web site. Once established, however, the Web site is inexpensive to maintain and far more affordable than paying for clinician time to deliver in-person lifestyle counseling. The net cost of adopting such a system therefore deserves study.

Enabling patients to use their computers more interactively for personal health management creates possibilities that far exceed the functions performed by the MHL Web site. ${ }^{26}$ Fully $94 \%$ of patients who visited our Web site were willing to answer online questions about health history. Systems that share such information with clinicians could obviate the need to sacrifice time during appointments for this task. Patients' answers can be used to update medical records, populate electronic health records, and prompt clinicians about health habits and clinical services needing attention. ${ }^{27-33}$

Users wanted the MHL Web site to provide greater detail and interactivity with clinicians. Future Web sites can enable patients to examine their records and test results, visit resource libraries and Web sites to broaden their knowledge, arrange live or asynchronous consultations with e-counselors, receive follow-up emails for reminders or reinforcement, and participate in longitudinal tracking for research. ${ }^{34-40}$ Whether offering these tools to patients improves health outcomes or satisfaction with care awaits further study with longer observational periods.

To read or post commentaries in response to this article, see it online at http://www.annfammed.org/cgi/content/full/4/2/148.

Key words: Diet, physical activity; smoking cessation; alcohol drinking; obesity; health promotion; practice-based research; communication; delivery of health care; health services research

Submitted April 29, 2005; submitted, revised, October 10, 2005; accepted October 26, 2005.

Funding support: This study was supported by a Robert Wood Johnson Foundation Prescription for Health grant (No. 049060).

Acknowledgments: We thank Marshall Thompson, David Williams, the Virginia Commonwealth University Department of Computer Sciences, and Creative Services, for their invaluable assistance in developing the Web site. Comments of the editors and anonymous reviewers regarding previous drafts of this manuscript were extremely helpful. We thank the management, medical staff and project champions at the 6 participating practices: Fairfax Family Practice Center, Fairfax; Broadlands Family Practice, Ashburn; Herndon Family Medicine, Herndon; Prince William Family Medicine, Manassas; Town Center Family Medicine, Reston; and Vienna Family Medicine, Vienna. We thank the American College of Preventive 
Medicine, our national partner, and our local partners: Fairfax County Park Authority, Fairfax-Falls Church Community Services Board - Alcohol and Drug Services, Inova Health System, and Community Alcohol Treatment Services. We also thank Russell E. Glasgow, PhD, Susan A. Flocke, $\mathrm{PhD}$, and Claudio R. Nigg, PhD, for their professional advice, and the staff of the national entities that gave further input on MHL: American Cancer Society, American Heart Association, American Diabetes Association, American Academy of Family Physicians, American College of Physicians, Agency for Healthcare Research and Quality, Centers for Disease Control and Prevention, and National Institutes of Health.

\section{References}

1. Mokdad AH, Marks JS, Stroup DF, Gerberding JL. Actual causes of death in the United States, 2000. JAMA. 2004;291:1238-1245.

1. Mokdad AH, Marks JS, Stroup DF, Gerberding JL. Correction: actual causes of death in the United States, 2000. JAMA. 2005;293:293-294.

2. Goldstein MG, Whitlock EP, DePue J. Multiple behavioral risk factor interventions in primary care. Summary of research evidence. Am J Prev Med. 2004;27:61-79.

3. Jaen CR, Stange KC, Tumiel LM, Nutting P. Missed opportunities for prevention: smoking cessation counseling and the competing demands of practice. J Fam Pract. 1997:45:348-354.

4. Zyzanski SJ, Stange KC, Langa D, Flocke SA. Trade-offs in high-volume primary care practice. J Fam Pract. 1998;46:397-402.

5. Jaen $C R$, Mcllvain $H$, Pol $L$, et al. Tailoring tobacco counseling to the competing demands in the clinical encounter. J Fam Pract. 2001;50:859-863.

6. Eden KB, Orleans CT, Mulrow CD, Pender NJ, Teutsch SM. Does counseling by clinicians improve physical activity? A summary of the evidence for the U.S. Preventive Services Task Force. Ann Intern Med. 2002;137:208-215.

7. Pignone MP, Ammerman A, Fernandez L, et al. Counseling to promote a healthy diet in adults: a summary of the evidence for the U.S. Preventive Services Task Force. Am J Prev Med. 2003;24:75-92.

8. Rosal MC, Ockene JK, Luckmann R, et al. Coronary heart disease multiple risk factor reduction. Providers' perspectives. Am J Prev Med. 2004;27:54-60.

9. Glanz K, Lewis FM, Rimer BK. Health Behavior and Health Education. San Francisco, Calif: Jossey-Bass; 60-84; 1997.

10. Fotheringham MJ, Owies D, Leslie E, Owen N. Interactive health communication in preventive medicine: internet-based strategies in teaching and research. Am J Prev Med. 2000;19:113-120.

11. Cifuentes M, Fernald DH, Green LA, et al. Prescription for health: changing primary care practice to foster healthy behaviors. Ann Fam Med. 2005;3 Suppl 2:\$4-11.

12. Department of Family Medicine, Virginia Commonwealth University. Virginia Ambulatory Care Outcomes Research Network. Available at: http://www.acorn.fap.vcu.edu.

13. Skeskin DJ. Handbook of Parametric and Nonparametric Statistical Procedures. 2nd ed. New York, NY: Chapman and Hall; 2000.

14. Woolf SH, Chan EC, Harris R, et al. Promoting informed choice: transforming health care to dispense knowledge for decision making. Ann Intern Med. 2005;143:293-300.

15. Pew Internet and American Life Project. Pew Internet and American Life Project. America's Online Pursuits. The changing picture of who's online and what they do. 2003. Available at: http://www.pewinternet. org/pdfs/PIP_Online_Pursuits_Final.PDF. Accessed: 21 April 2005.

16. Tang PC, Lansky $D$. The missing link: bridging the patient-provider health information gap. Electronic personal health records could transform the patient-provider relationship in the twenty-first century. Health Aff (Millwood). 2005;24:1290-1295.

17. Robert Wood Johnson Foundation. \$3 Million in Grants Awarded to Help Primary Care Providers Promote Healthy Behaviors Among Their Patients (press release). Available at: http://www.rwjf.org/newsroom/newsreleasesdetail.jsp?id = 10357. Accessed: 5 October 2005 .
18. Pew Internet and American Life Project. Internet Use by Region in the United States: Regional Variations in Internet Use Mirror Differences in Educational and Income Levels. Washington, DC: Pew Internet and American Life Project; 2003.

19. Krist AH, Woolf SH, Rothemich SF, Johnson RE, Wilson DB. It takes a partnership: the value of collaboration in developing and promoting a Web site for primary care patients. Ann Fam Med. 2005;3 Suppl 2: S47-49.

20. Whitlock EP, Polen MR, Green CA, Orleans T, Klein J. Behavioral counseling interventions in primary care to reduce risky/harmful alcohol use by adults: a summary of the evidence for the U.S. Preventive Services Task Force. Ann Intern Med. 2004;140:557-568.

21. Carpiano RM, Flocke SA, Frank SH, Stange KC. Tools, teamwork, and tenacity: an examination of family practice office system influences on preventive service delivery. Prev Med. 2003;36:131-140.

22. Dickey LL, Gemson DH, Carney P. Office system interventions supporting primary care-based health behavior change counseling. Am J Prev Med. 1999;17:299-308.

23. Woolf SH, Glasgow RE, Krist A, et al. Putting it together: finding success in behavior change through integration of services. Ann Fam Med. 2005;3 Suppl 2:S20-27.

24. Hedley $A A$, Ogden $C L$, Johnson $C L$, et al. Prevalence of overweight and obesity among US children, adolescents, and adults, 1999-2002. JAMA. 2004:291:2847-2850.

25. Flegal KM, Graubard BI, Williamson DF, Gail MH. Excess deaths associated with underweight, overweight, and obesity. JAMA. 2005;293:1861-1867.

26. Martin JC, Avant RF, Bowman MA, et al. The Future of Family Medicine: a collaborative project of the family medicine community. Ann Fam Med. 2004;2 Suppl 1:S3-32.

27. The Decade of Health Information Technology: Delivering ConsumerCentric and Information-Rich Health Care, Framework for Strategic Action. Washington, DC: US Department of Health and Human Services.

28. Kittler AF, Carlson GL, Harris C, et al. Primary care physician attitudes towards using a secure web-based portal designed to facilitate electronic communication with patients. Inform Prim Care. 2004;12:129-138.

29. Balas EA, Austin SM, Mitchell JA, et al. The clinical value of computerized information services. A review of 98 randomized clinical trials. Arch Fam Med. 1996;5:271-278.

30. Hunt DL, Haynes RB, Hanna SE, Smith K. Effects of computer-based clinical decision support systems on physician performance and patient outcomes: a systematic review. JAMA. 1998;280:1339-1346.

31. Shea S, DuMouchel W, Bahamonde L. A meta-analysis of 16 randomized controlled trials to evaluate computer-based clinical reminder systems for preventive care in the ambulatory setting. J Am Med Inform Assoc. 1996;3:399-409.

32. Balas EA, Weingarten $S$, Garb $C T$, et al. Improving preventive care by prompting physicians. Arch Intern Med. 2000;160:301-308.

33. Grimshaw JM, Shirran L, Thomas R, et al. Changing provider behavior: an overview of systematic reviews of interventions. Med Care. 2001;39:112-45.

34. Strecher VJ, Greenwood T, Wang C, Dumont D. Interactive multimedia and risk communication. J Natl Cancer Inst Monogr. 1999:134-139.

35. Wald JS, Middleton B, Bloom A, et al. A patient-controlled journal for an electronic medical record: issues and challenges. Medinfo. 2004;11:1166-1170.

36. Harris LM. Health and the New Media: Technologies Transforming Personal and Public Health. Mahwah, NJ: Lawrence Erlbaum Associates; 1995.

37. Street RL, Gold WR, Manning TE. Health Promotion and Interactive Technology: Theoretical Applications and Future Directions. London, England: Lawrence Erlbaum Associates; 1997.

38. Tate DF, Zabinski MF. Computer and Internet applications for psychological treatment: update for clinicians. J Clin Psychol. 2004;60:209-220.

39. Chin T. Online consultation: what's it worth? AMNews, June 10, 2002.

40. Tate DF, Jackvony EH, Wing RR. Effects of Internet behavioral counseling on weight loss in adults at risk for type 2 diabetes: a randomized trial. JAMA. 2003;289:1833-1836. 